\title{
Detection and widespread distribution of Chlamydia pneumoniae in the vascular system and its possible implications
}

\author{
G Ong, B J Thomas, A O Mansfield, B R Davidson, D Taylor-Robinson
}

\begin{abstract}
Aims-To attempt to detect Chlamydia pneumoniae DNA in atheromatous vascular tissue.

Methods-A modification of an existing polymerase chain reaction (PCR) assay and immunofluorescence staining with a monoclonal antibody directed against $C$ pneumoniae were used to detect $C$ pneumoniae. Specimens from 32 patients undergoing abdominal aortic aneurysm repair were examined. Vascular tissue, ostensibly normal, from six liver transplant donors was also examined for comparison. Altogether, 43 vessels from these 38 subjects (age range 36-85 years) were examined.

Results-C pneumoniae was detected in $11(44 \%)$ of 25 aortas, five (55\%) of nine iliac arteries, two $(40 \%)$ of five femoral arteries, and one of two iliac veins. Immunofluorescence staining supported positive PCR results in three of 12 cases in which it was used. Overall, $C$ pneumoniae was detected in the arteries of $14(44 \%)$ of the patients undergoing vascular surgery and three $(50 \%)$ of the donors.

Conclusions-This study is the first in the $\mathrm{UK}$ in which $C$ pneumoniae organisms have been found in atherosclerotic vessels and the tendency for the organisms to be present most often in such vessels exhibiting chronic inflammatory changes suggests that a search for them in various forms of arteritis may also be rewarding. (f Clin Pathol 1996;49:102-106)
\end{abstract}

Keywords: Chlamydia pneumoniae, vascular tissue, PCR.

Chlamydia pneumoniae is a human pathogen, one of the four species of the genus Chlamydia. ${ }^{1}$ It causes a range of respiratory tract diseases, including pharyngitis, sinusitis, bronchitis, mild to severe pneumonia, ${ }^{2}$ and asthma. ${ }^{3}$ Serological and epidemiological studies have shown that the organisms are widespread geographically, ${ }^{4}$ and that epidemics occur in four, six and 10 yearly cycles.

IgG antibody to $C$ pneumoniae is detected rarely in children up to five years of age, but is present in half of the adult population at any one time, suggesting a cycle of infection and reinfection during a lifetime. ${ }^{5}$ IgG antibody increases with age so that it is found in almost all subjects aged 70 years. Seroconversion usually occurs between eight and 16 years of age ${ }^{6}$ and there is a higher rate of infection among men than women. ${ }^{7}$

Apart from being a respiratory pathogen, $C$ pneumoniae has been associated serologically with coronary heart disease and myocardial infarction. ${ }^{89}$ More direct evidence, based on electron microscopy, immunocytochemistry and the polymerase chain reaction (PCR), of its existence in plaques of coronary arteries and in aortic lesions has been found by one group of investigators ${ }^{10-13}$ but not by another who used PCR only. ${ }^{14}$ In view of the controversy, we have used PCR and immunofluorescence techniques and provide the first evidence that in the UK $C$ pneumoniae exists in various atherosclerotic arteries, in many of which chronic inflammatory changes are a notable feature.

\section{Methods}

TISSUE AND DNA EXTRACTION

Atheromatous arterial tissue was obtained from 29 men and three women who were undergoing surgery at St Mary's Hospital, London, mainly for repair of aortic aneurysms. The tissues were collected within three hours from the operating theatre, washed with phosphate buffered saline (PBS), and dissected aseptically into a number of pieces. Vascular tissues were also obtained from three male and three female liver transplant donors at the Royal Free Hospital, London, on the basis that these might provide normal tissue for comparison. After excision, these specimens were kept in a Ringer's solution at $4^{\circ} \mathrm{C}$ for a few days before being washed and dissected aseptically. Blood samples were not obtained from any subjects in this study.

One piece of dissected tissue was processed for DNA extraction in the following way. Tissue was frozen in liquid nitrogen and pulverised rapidly while still frozen in a pre-cooled mortar and pestle. The powder was scooped into a microcentrifuge tube containing $10 \mathrm{mM}$ Tris, $75 \mathrm{mM} \mathrm{NaCl}, 25 \mathrm{mM}$ EDTA. To avoid crosscontamination, a different mortar and pestle and a different set of instruments were used 
C pneumoniae detected by a PCR assay in the wall of blood vessels

\begin{tabular}{lrl}
\hline Vessel* & $\begin{array}{l}\text { No. of vessels } \\
\text { tested }\end{array}$ & $\begin{array}{l}\text { No. (\%) } \\
P C R \text { positive }\end{array}$ \\
\hline Subjects undergoing vascular & & \\
repair & 25 & $11(44 \%)$ \\
Aorta & 3 & $2(67 \%)$ \\
Iliac & 5 & $2(40 \%)$ \\
Femoral & 1 & 0 \\
Renal & 1 & \\
Popliteal & & $3(50 \%)$ \\
Liver transplant donors & 6 & 1 \\
Iliac & 2 & $19(44 \%)$ \\
Iliac vein & 43 & $17(45 \%)$ \\
Total & 38 & \\
Patients & & \\
\hline
\end{tabular}

* Arteries except where indicated.

for each tissue. All these pieces of apparatus were washed, soaked in $4 \mathrm{M} \mathrm{HCl}$, and finally rinsed overnight in distilled water before re-use. The tissue suspension was thoroughly mixed, sodium lauryl sulphate added to a final concentration of $0.5 \%$, and the mixture incubated at $37^{\circ} \mathrm{C}$ for one hour. Proteinase $\mathrm{K}$ was then added to a final concentration of $20 \mu \mathrm{g}$ per $\mathrm{ml}$. After further incubation at $55^{\circ} \mathrm{C}$ for two hours, the debris was removed by centrifugation and an equal volume of $\mathrm{phenol} / \mathrm{chloroform} /$ isoamyl alcohol $(25: 24: 1)$ was added to the supernatant fluid. Following a second extraction step, DNA

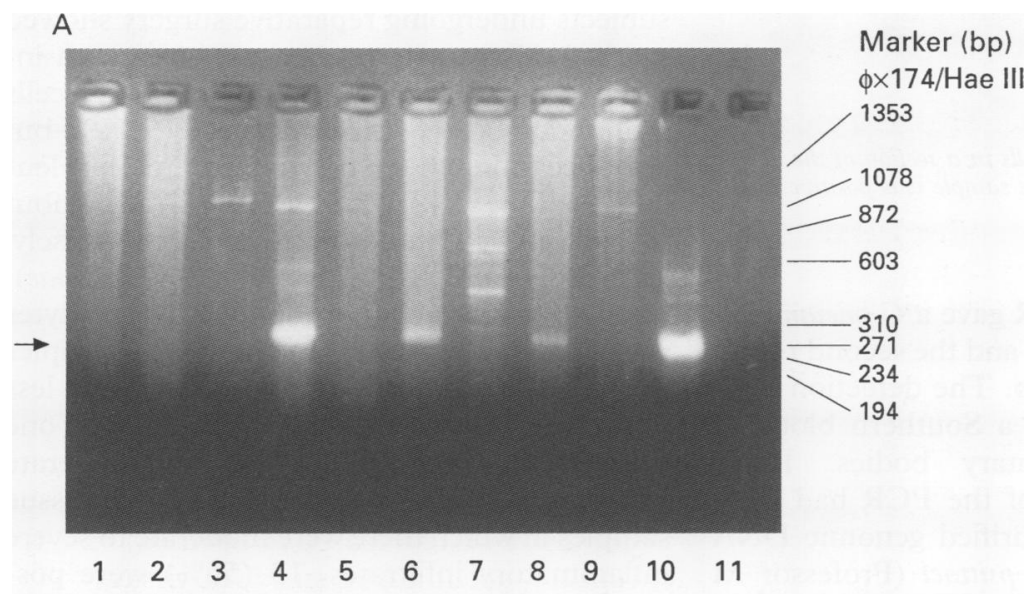

B

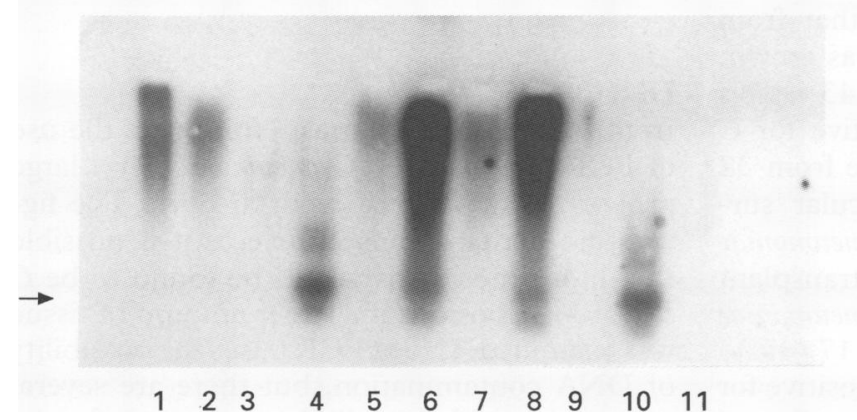

Figure 1 Detection of C pneumoniae DNA from patient samples. DNA products from the nested PCR assay were electrophoresed on an agarose gel $(A)$ and probed by Southern hybridisation (B) with an oligonucleotide probe containing a DNA sequence internal to the primer sequences used in the nested PCR. Lanes 4, 6 and 8, C pneumoniae positive; lanes $1-3,5,7$, and $9, \mathrm{C}$ pneumoniae negative; lane 10, positive control of

C pneumoniae DNA; lane 11, negative control comprising water. Results of the gel electrophoresis agree with those obtained by the Southern blot. The arrows indicate the $P C R$ product of $227 \mathrm{bp}$. The marker used was $\phi X 174 / \mathrm{HaeIII}$. was precipitated at $-20^{\circ} \mathrm{C}$ overnight with $0 \cdot 1$ volume of $3 \mathrm{M}$ sodium acetate and $2 \cdot 5$ volumes of ethanol.

\section{POLYMERASE CHAIN REACTION FOR $C$} PNEUMONIAE

A nested PCR assay was developed for the detection of $C$ pneumoniae. The primers were based on the DNA sequence of the major outer membrane protein (MOMP) of $C$ pneumoniae. Primers for the first round of the PCR (APN1 and APN2) ${ }^{15}$ were provided by Adam Cunningham (Department of Microbiology, Southampton University Medical School, Southampton, UK). Primers for the second round of the PCR were designed by us and gave a PCR product of 227 base pairs (bp). Although there are several regions of homology within the DNA sequence of the MOMP gene to $C$ psittaci and $C$ trachomatis, we have especially chosen the primer sequences from the variable domains of the coding region so that the primers will not amplify a product from the other two species but will have specificity only for $C$ pneumoniae. The first primer, TGCCAACAGACGCTGGCGTAGCAA, spans bases 1053 to 1076 of the MOMP gene while the second primer, TAACTGCATGGAACCCTTCTTTACTAG, spans bases 1254 to 1280 of the MOMP gene. We determined that use of the second round PCR assay enabled as few as 10 organisms to be detected. Amplified products were electrophoresed on a $2 \%$ agarose gel and specimens were regarded as positive when the band migrated to the expected molecular weight of the positive controls (fig 1). A positive control of $C$ pneumoniae DNA and a negative control comprising water were included in each PCR assay. Positive results were confirmed by Southern blot hybridisation with a $30 \mathrm{bp}$ oligonucleotide probe. Evidence for the existence of Mycoplasma fermentans in the tissues was also sought by means of a PCR assay that has been described and used previously. ${ }^{16}$ To avoid DNA contamination during the assays, separate hoods were used for mixing pre-PCR reagents and for adding DNA from clinical material and a different room was used for adding amplified DNA product from the first round PCR.

IMMUNOCHEMICAL STAINING AND HISTOLOGY A piece of tissue adjacent to the piece from which DNA was extracted for the PCR was frozen in isopentane; frozen sections were cut and examined by using an indirect immunofluorescence technique for $C$ pneumoniae elementary bodies with a specific monoclonal antibody and adjacent frozen sections by using an avidin-biotin-peroxidase method (Dako, High Wycombe, UK). Sections were also stained with haematoxylin and eosin for histological examination.

Results

The PCR assay was evaluated first for sensitivity and specificity. The primers for the first 


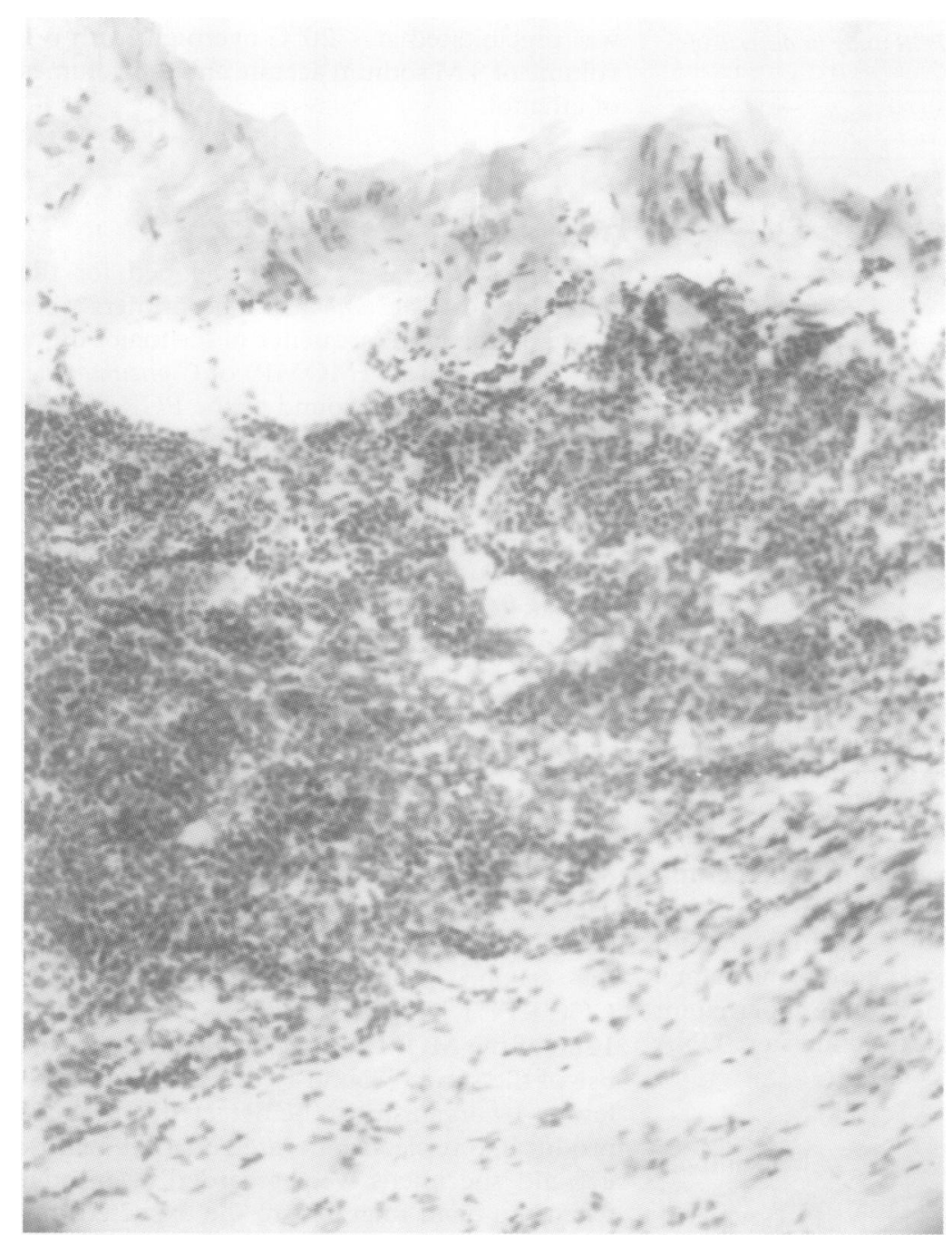

Figure 2 Atheromatous changes and chronic inflammatory cells in a section of the abdominal aorta (haematoxylin and eosin). An adjacent tissue sample was positive for $\mathrm{C}$ pneumoniae by PCR. firmed in this way, as were all initially negative results. In tests on specimens from liver transplant donors, the specimens were not consistently positive on repeat testing but they were always positive more than once. Only 12 of the vascular repair specimens were examined by immunofluorescence staining. Four were unreadable because of non-specific staining, five were negative and three were positive; one of the unreadable specimens and the three fluorescence positive specimens were also positive on PCR. It is clear that $C$ pneumoniae organisms were not restricted to the aorta, being detected in about the same proportion of iliac and femoral arteries, and in one of two iliac veins examined. In one subject both the aorta and the femoral artery tested were PCR positive, whereas in another, the aorta but not a renal artery was PCR positive.

There was no correlation between age and a positive PCR result. Thus, for patients undergoing vascular surgery, the mean age of those who had PCR positive vessels was 69 years and that of subjects who had PCR negative vessels was 73 years. Liver transplant donors were younger (mean age, 50 years) but, again, there was no difference between the age of PCR positive and negative subjects.

Specimens were also tested by a PCR assay for $M$ fermentans. Of 19 specimens that were positive for $C$ pneumoniae, one was also positive for $M$ fermentans.

Histologically, all of the tissue samples from subjects undergoing reparative surgery showed marked atheromatous changes, often with infiltrates mainly of chronic inflammatory cells (lymphocytes and macrophages) (fig 2), but also occasionally of polymorphonuclear leucocytes. The cells were dispersed throughout the vessel wall and/or were grouped densely. In one case (PCR positive for $C$ pneumoniae), the presence of polymorphonuclear leucocytes was the striking feature. The tissue samples from the liver transplant donors were far less affected by atheromatous changes and only one of seven samples examined showed a moderate inflammatory infiltrate. Overall, of 23 tissue samples in which there were moderate to severe inflammatory infiltrates, $13(56 \%)$ were positive for $C$ pneumoniae on PCR; of the 16 tissue samples in which there were no or minimal infiltrates, five $(31 \%)$ were positive on PCR. round PCR also did not amplify DNA from these two chlamydial species, nor that from Hep2 cells in which $C$ pneumoniae was grown.

As shown in the table, 19 (44\%) of 43 vessels tested by the PCR assay were positive for $C$ pneumoniae (fig 1). The vessels came from 32 subjects undergoing reparative vascular surgery, 14 (44\%) of whom had $C$ pneumoniae positive vessels. There were six liver transplant donors, three (50\%) of whom had $C$ pneumoniae positive vessels (iliac arteries). Thus, 17 (45\%) of 38 subjects had vessels that were positive for $C$ pneumoniae. The PCR results were confirmed either by amplifying a further sample of DNA extracted from the same piece of tissue and/or by amplifying DNA from another piece of tissue from the same vessel. In tests on specimens from subjects undergoing vascular repair, all but three initially positive results were con-

\section{Discussion}

In this study, based almost entirely on the use of PCR, we detected $C$ pneumoniae in a large proportion of various major arteries. The figures are perhaps conservative as it is possible that more specimens would be found to be $C$ pneumoniae positive if a larger amount of tissue was examined. Use of PCR raises the possibility of DNA contamination, but there are several reasons why this is unlikely to account for the results. First, specimens were processed and tested in small groups reducing the possibility of contamination; second, negative controls within each assay remained negative; third, reamplifying the DNA from the same specimen or testing another piece of tissue from the same 
vessel produced the same result for all but three of the 43 tissue samples tested; and fourth, specimens that were recorded independently as fluorescence positive were also positive for $C$ pneumoniae by PCR. Considerable difficulty was experienced in examining specimens by the immunofluorescence technique because of non-specific background staining and the morphological heterogeneity of $C$ pneumoniae elementary bodies in contrast to the homogeneity of $C$ trachomatis bodies. As a consequence, not all specimens were examined and only those that could be regarded confidently as fluorescence positive were so recorded. Even greater difficulty was encountered with the immunoperoxidase test, in which a problem of nonspecific staining, not mentioned by others, ${ }^{11} 12$ has not yet been resolved.

There was a tendency for more of the tissue samples that had moderate to severe chronic inflammatory changes to be positive for $C$ pneumoniae than those that had few inflammatory changes. While this is consistent with the known ability of chlamydial organisms to produce chronic disease with scarring, trachoma and pelvic inflammatory disease being good examples, it would be unwise to over-interpret the observation as sections of some PCR positive specimens contained few or no inflammatory cells and some PCR negative specimens contained many. It was perhaps too much to expect that vessels from organ transplant donors would be free of atheromatous changes. They did, in fact, show some such changes histologically but little evidence of inflammation compared with the tissue samples from the patients who underwent reparative surgery. However, although about the same proportion of the donor tissue samples and the more atheromatous tissue samples were positive by PCR, there were probably fewer organisms in the former as indicated by the difficulty in finding them consistently. Whether this means that healthy non-atheromatous tissue is free of $C$ pneumoniae, as Kuo et $a l^{11}$ suggest, is in our opinion still a moot point and is an issue that requires further study. However, if $C$ pneumoniae is found only in diseased tissue and not in healthy tissue, it could mean that it has been deposited in an atheromatous area that already exists, perhaps being transported there in chronic inflammatory cells, and has nothing to do with initiating the process. As $M$ fermentans, which is known to escape from mucosal surfaces into the blood stream and is associated with iymphocytes, ${ }^{16}$ was detected on one occasion only, $C$ pneumoniae by contrast would seem to be specifically associated with the atheromatous inflammatory lesions at some stage. Of course, this does not preclude a role for other micro-organisms. The difficulty in attempting to resolve the "chicken or egg" problem in the case of $C$ pneumoniae is that completely atheroma-free arterial tissue from individuals old enough to have experienced a $C$ pneumoniae infection is not easy to find. However, examination of postmortem tissue in which the presence or absence of overt and histological changes are correlated with the presence or absence of $C$ pneumoniae, based on the PCR, would seem a sensible way to proceed, particularly if this is done for individuals of different ages. The finding of $C$ pneumoniae in a vein was surprising and invites further investigation. Easy access to venous tissue removed because of varicosities should permit rapid determination of the extent to which veins might be involved.

The detection and measurement of $C$ pneumoniae antibodies in seroepidemiological surveys has been helpful in suggesting a role for this organism in coronary heart disease ${ }^{89}$ but we do not believe that serology is useful in relatively elderly patients as a means of defining, on an individual basis, the role of the organisms in the atheromatous disease process. However, if the organisms could not be detected in the vessels of young people, the presence of specific antibody would be useful in indicating that they had been infected at some time and at least had had the opportunity for vessel involvement. Furthermore, the notion that $C$ pneumoniae antibody might be protective based on the absence of organisms in the vessels of patients with high antibody titres ${ }^{11}$ needs to be clarified.

We believe that attempts should be made to develop an animal model of $C$ pneumoniae in atheroma, possibly murine in view of the success achieved with such a model of $C$ trachomatis genital tract disease. ${ }^{17}$ In addition, the judicious use of broad-spectrum antibiotics, such as tetracyclines and erythromycin, may be worthwhile. Administration of such antibiotics to patients undergoing coronary artery by-pass surgery to discover whether they increased the time to re-stenosis would be one approach. The use of a $C$ pneumoniae vaccine which if not capable of preventing colonisation in the respiratory tract might at least prevent or reduce haematogenous spread of the organisms to other sites is a possible future consideration. Finally, the presence of $C$ pneumoniae organisms in atheromatous tissue, which usually contains chronic inflammatory cells, raises another question. Are these organisms involved in the various forms of arteritis in which there is a chronic inflammatory response - for example, temporal arteritis, the aetiology of which is ill-understood? Examination of stored tissue samples should expedite the answer.

We thank Sister Miriam Bland (St Mary's Hospital), Dr Rob Goldin (St Mary's Hospital Medical School), and Mr Adam Cunningham and Professor Michael Ward (Southampton University Medical School) for their help in this study.

1 Grayston JT, Campbell LA, Kuo CC, Mordhurst CH, Saikku P, Thom DH, et al. A new respiratory tract patho-
gen: Chlamydia pneumoniae strain TWAR. $\mathcal{F}$ Infect Dis gen: Chlamydia p

2 Grayston JT. Infections caused by Chlamydia pneumoniae strain TWAR. Clin Infect Dis 1992;15:757-63.

3 Hahn DL, Dodge RW, Golubjatnikov R. Association of Chlamydia pneumoniae (strain TWAR) infection with wheezing, asthmatic bronchitis and adult-onset asthma. fAMA 1991;266:225-30.

4 Forsey T, Darougar S, Treharne JD. Prevalence in human beings of antibodies to Chlamydia IOL-207, an atypical strain of Chlamydia. $\mathcal{F}$ Infect Dis 1986;12:145-52.

5 Grayston JT. Chlamydia pneumoniae, strain TWAR. In: Bowie WR, Caldwell HD, Jones RP, Mårdh P-A, Ridgway Bowie WR, Caldwell HD, Jones RP, Mårdh P-A, Ridgway GL, Schachter J, et al, eds. Chlamydial infections. Caridge: Cambridge University Press, 1990:389-401.

6 Haidl S, Sveger T, Persson K. Longitudinal pattern of antibodies to Chlamydia pneumoniae in children: In: antibodies to Chlamydia pneumoniae in children: In: $\mathrm{RB}$, Ridgway GL, et al, eds. Chlamydial infections. Bologna: Società Editrice Esculapio, 1994:189-92. 
7 Karvonen M, Tuomilheto J, Pitkaniemi J, Saikku P. The epidemic cycle of Chlamydia pneumoniae infection in eastern Finland. Epidemiol Infect 1993;110:349-60.

8 Saikku P, Leinonen M, Mattila K, Ekman MR, Nieminen MS, Mäkelä PH, et al. Serological evidence of an association of novel Chlamydia, TWAR, with chronic coronary heart disease and acute myocardial infarction. Lancet 1988;ii:983-6.

9 Thom DH, Wang SP, Grayston JT, Siscovick DS, Stewart DK, Kronmal RA, et al. Chlamydia pneumoniae strain TWAR antibody and angiographically demonstrated coronary heart disease. Arterioscler Thromb 1991;11:547-51.

10 Shor A, Kuo CC, Patton DL. Detection of Chlamydia pneumoniae in coronary arterial fatty streaks and atherpneumoniae in coronary arterial fatty streaks and
omatous plaques. $S$ Afr Med $\mathcal{F} 1992 ; 82: 158-61$.

11 Kuo CC, Shor A, Campbell LA, Fukushi H, Patton DI Grayston JT. Demonstration of Chlamydia pneumonia in atherosclerotic lesions of coronary arteries. $\mathcal{F}$ Infect Dis 1993;167:841-9.

12 Kuo CC, Gown AM, Benditt EP, Grayston JT. Detection of Chlamydia pneumoniae in aortic lesions of atherosclerosis by immunocytochemical stain. Arterioscler Thromb 1993;13:1501-4.

13 Campbell LA, O'Brien ER, Cappuccio AL, Kuo C-C, Wang $\mathrm{S}-\mathrm{P}$, Stewart D, et al. Detection of Chlamydia pneumoniae in atherectomy tissue from patients with symptomatic coronary artery disease. In: Orfila J, Byrne GI, Chernesk $\mathrm{MA}$, Grayston JT, Jones RB, Ridgway GL, et al, eds Chlamydial infections. Bologna: Società Editrice Esculapio, 1994:212-15.

14 Weiss S, Roblin P, Gaydos C, Cummings P, Patton D, Schulhoff N, et al. Failure to detect Chlamydia pneumoniae $(\mathrm{Cp})$ in coronary atheromas of patients undergoing atherectomy. In: Orfila J, Byrne GI, Chernesky MA, Grayston JT, Jones RB, Ridgway GL, et al, eds. Chlamydial infections. Bologna: Società Editrice Esculapio, 1994:220-3.

15 Cunningham A, Johnston S, Julious S, Sillis M, Ward ME. The role of Chlamydia pneumoniae and other pathogens in acute episodes of asthma in children. In: Orfila J, Byrn GI, Chernesky MA, Grayston JT, Jones RB, Ridgway GL, et al, eds. Chlamydial infections. Bologna: Società Editrice Esculapio, 1994:480-3. 16 Katseni VL, Gilroy CB, Ryait BK, Ariyoshi K, Bieniasz PD,
Weber JN, et al Mycoplasma fermentans in individuals seropositive and seronegative for HIV-1. Lancet 1993;341: 271-3.

17 Tuffirey $M$, Alexander F, Taylor-Robinson D. Severity of salpingitis in mice after primary and repeated inoculation with a human strain of Chlamydia trachomatis. $\mathcal{F}$ Exp Pathol 1990;71:403-10. 